\title{
Predictors of Parental Coping During the Covid-19 Pandemic: A Survey in Germany
}

\author{
Vera Clemens*, Franziska Köhler-Dauner, Ute Ziegenhain and Jörg M. Fegert \\ Hospital of Child and Adolescent Psychiatry/Psychotherapy, University of Ulm, Ulm, Germany
}

The Covid-19 pandemic has been profoundly affecting nearly everybody, but families with minors have been hit particularly. Closure of schools and kindergartens, home schooling, and working from home have led to a profound upheaval in family life. Parental adverse childhood experiences (ACEs) are an important determinant for parenting behavior. Importantly, ACEs can increase the vulnerability to stress and impair coping strategies. The current pandemic leads to increased parental stress, a risk factor for harsh parenting behavior, Therefore, we aimed to assess the role of ACEs and sociodemographic factors

OPEN ACCESS

Edited by:

Nadya Golfenshtein,

University of Haifa,

Israel

Reviewed by:

Serena Di Giandomenico,

University of Urbino Carlo Bo, Italy

Thorsten Mikoteit,

University of Basel,

Switzerland

*Correspondence: Vera Clemens

vera.clemens@uni-ulm.de

Specialty section:

This article was submitted to Personality and Social Psychology,

a section of the journal

Frontiers in Psychology

Received: 26 May 2021

Accepted: 10 August 2021

Published: 10 September 2021

Citation:

Clemens V, Köhler-Dauner F, Ziegenhain U and Fegert JM (2021) Predictors of Parental Coping During the Covid-19 Pandemic: A Survey in

Germany.

Front. Psychol. 12:715327. doi: 10.3389/fpsyg.2021.715327 associated to parental coping during the current pandemic. In a cross-sectional online survey, 687 parents of minors in Germany were included. Demographic and psychosocial factors associated to parental coping during the first lockdown due to the Covid-19 pandemic were assessed. Results show that younger age of the respective child, income loss, dissatisfaction with the sharing of childcare duties, and ACEs were significantly associated with an increase of potential harmful parenting behavior during the Covid-19 pandemic. An increase of dissatisfaction with the sharing of childcare duties during the pandemic was predicted by working from home and taking care of the children mainly by oneself, while sharing childcare duties with the partner equally resulted even in an increase of satisfaction with sharing of childcare duties during the pandemic. These findings demonstrate that a history of childhood adversity in a parent is a risk factor for harmful parenting during the pandemic. Parental satisfaction with sharing of caregiving is an important factor for parental coping during the pandemic. Sharing of caregiving between partners should be encouraged.

Keywords: COVID-19, pandemic, adverse childhood experiences, parental coping, child maltreatment

\section{INTRODUCTION}

Since the beginning of the Covid-19 pandemic, life of families all over the world has changed unprecedentedly. An estimated $90 \%$ or more of children and adolescents globally have faced the effects of school closures (UNESCO, 2020). Social contacts have been limited, out-of-home leisure time activities have been canceled (Imperial College COVID-19 Response Team, 2020). Parents have had to support children with home schooling, while working from home in parallel. Financial pressure has risen in many families due to unemployment and wage cuts. Economic problems can lead to feelings of stress and consequent marital conflict (Elder, 1974; 
Elder and Conger, 2000). Altogether, this can severely affect parenting and - in the worst case - erupt in physical and psychological violence among families (Fegert et al., 2020a). First official data point toward an increase of child maltreatment during the pandemic (Nguyen, 2021; Salt et al., 2021).

The course of the current pandemic is hard to predict. Although, a first strict lockdown has ended in most parts of the world, several following pandemic waves have hit many countries and some even face or have seen new lockdowns. Therefore, it is important to identify predictors of families who struggle to master the situation and who consequently may need more support. The number of studies assessing parenting during the pandemic have been rising. They point toward high levels of stress (Marchetti et al., 2020; Romero et al., 2020; van Tilburg et al., 2020), anxiety, and financial burden (Fong and Iarocci, 2020) among parents and parentingrelated exhaustion (Marchetti et al., 2020) during the pandemic. Importantly, higher levels of parental stress was shown to be associated with harsh parenting behavior and poorer parent child relationship since the beginning go of the pandemic (Chung et al., 2020; Romero et al., 2020).

One factor that may be of importance on how parents deal with pandemic-associated stressors are adverse childhood experiences (ACEs). ACEs include child maltreatment, in detail emotional, physical, and sexual abuse as well as emotional and physical neglect, and household dysfunction, comprising e.g., mental illness and substance abuse of any household member, violence against the mother, parental separation, and incarceration of a household member (Hughes et al., 2017). ACEs are frequent. In the German population, more than $40 \%$ have experienced at least one type of ACE, and nearly $9 \%$ have experienced four or more (Witt et al., 2019). Even in less stressful times, ACEs increase the risk for psychosocial and economic impairments as well as mental and somatic health problems in a dose-dependent manner (Felitti et al., 1998; Norman et al., 2012; Rehkopf et al., 2016; Clemens et al., 2018). Furthermore, ACEs can significantly impair attachment and relationships in later life (Thomson and Jaque, 2017), just as the relation to one's own children. ACEs can significantly affect parenting (Bailey et al., 2012) and increase the risk for harmful parenting behavior including child maltreatment (Dixon et al., 2005a,b; DuMont et al., 2007; Bailey et al., 2012; Clemens et al., 2019). This so called cycle of violence was initially based on the research finding that physical abuse is an important predictor for violence in adulthood (Hunter and Kilstrom, 1979). It describes the intergenerational transmission of violent behavior - although, it is important to emphasize that most abused and neglected children do not turn violent themselves (Wright et al., 2019). However, experience of violence during childhood is the strongest predictor for the use of violence as disciplinary method for one's own children (Witt et al., 2017).

The experience of adversity during childhood affects the long-term individual stress response (Bunea et al., 2017) and can increase vulnerability to stress and impair successful coping of stressful situations by increased emotional reactivity and decreased emotion regulation (Hein and Monk, 2017; Duffy et al., 2018). A purposeful response to a stressful or challenging life event such as a pandemic on the other hand can be understood as coping (Compas et al., 2017). The experience of ACEs during childhood is suggested to result in perceiving the environment as threatening and unpredictable, leaving no or little opportunity to impact or change the environment (Sheffler et al., 2019). Consequently, ACEs are associated with less successful coping strategies of stressful situations (Leitenberg et al., 2004). During the pandemic, the majority of parents feel stressed by social distancing and closure of schools and childcare facilities (Calvano et al., 2021), resulting in increased perceived parenting stress (Brown et al., 2020). Thus, a significant impact of ACEs on coping and parenting strategies during the pandemic can be assumed. Recently, in a smaller sample of mothers, we were able to demonstrate that maternal ACEs are associated with endangered parenting behavior during the current pandemic (Köhler-Dauner et al., 2021). To the best of our knowledge, however, besides, data on the role of parental ACEs are missing. Moreover, as ACEs are associated with other important predictors such as economical impairment, psychosocial well-being, and parenting, they may influence these other factors. Importantly, parental stress was already shown to be a risk factor for child maltreatment during the pandemic, such as job loss, and younger age of the parent and the child (Lawson et al., 2020; Calvano et al., 2021).

Here, we aimed to assess the role of ACEs and sociodemographic factors associated topotential harmful parenting actions and parental coping of the current pandemic. The hypothesis was that parents are at higher risk for less successful coping and harmful parenting behavior during the pandemic when they were exposed to ACEs themselves.

\section{MATERIALS AND METHODS}

\section{Study Design}

We have conducted a cross-sectional online survey, which was available from May 18th to July 21th 2020. The first lockdown in Germany began on March 23, 2020 and ended via gradual relaxations - the first schools reopened on April 22, the openings of schools and kindergartens stretched to the end of June 2020. Inclusion criteria were age above 18 years and informed consent. Information on the survey was distributed by our clinical homepage, social media, and print media and existing mailing lists from other studies and interested parties. In total, 1,399 participants have participated in the online survey. For the here presented analyses, only data of participants who stated to be currently parent of a minor were assessed $(N=687)$.

\section{Ethics}

Information on the study and data analysis were given, electronic informed consent was obtained from each participant. Participation was anonymous. Participants could withdraw from 
the survey at any moment without providing any justification. The study was conducted in accordance with the Declaration of Helsinki. After consultation with the ethics committee of the University of Ulm, due to the anonymous character of the survey, there was no requirement for an ethics vote.

\section{Measures}

Socio-demographic questions included age, gender, educational level, and change of income during the pandemic and whether the participant has worked from home during the pandemic. In detail, the questions were "Did you work from home in the meantime during the start of the Covid-19 pandemic," "Has the income available in your household fallen by more than a quarter since the start of the Covid-19 pandemic?", "Who took care of the child during most of the time during the Covid-19 pandemic?", "Please indicate on a scale of $0-100$ how satisfied you are with the sharing of childcare duties between you and your partner (before the pandemic and now). The best conceivable satisfaction is marked with a '100', the worst with '0.”' “To what extent do the following statements apply to you? Since the beginning of the Covid-19 pandemic...(1) stands for 'does not apply at all,' (7) for 'applies very much' - ...I yell more at the child/...Am I more impatient with the child/...Am I increasingly afraid that my hand to smack the child/... Am I increasingly afraid that my partner will smack the child" and "Summarized, on a scale from 0 to $100 \ldots .,(0)$ stands for 'miserable', (100) stands for 'excellent,' - ... how well have you mastered the challenges of the Covid-19 pandemic to date?/...how well the child has mastered the challenges of the Covid-19 pandemic/...how well the family has mastered the challenges of the Covid-19 pandemic."

Regarding potential harmful parenting behavior, it was asked whether participants have yelled more at the child, whether they had been more impatient with the child, whether they had been more afraid to smack the child and whether they had been more afraid that their partner would smack the child since the beginning of the pandemic. Answers were possible on a Likert scale of 1-7, where (1) stood for "does not apply at all" and (7) for "applies very strongly."

Moreover, the participants were asked about parental satisfaction with the sharing of childcare duties before and during the pandemic and their assessment of how they, their children, and their family had dealt with the challenges of the pandemic (all answers: Likert scale 0 for worst and 100 for best).

The ACEs were assessed using the German version of the ACEs Questionnaire, a standard tool for retrospective assessment of ACEs with satisfactory reliability (Cronbachs $\alpha=0.76$; Wingenfeld et al., 2011). With the ACE Questionnaire, five forms of child maltreatment (physical abuse, emotional abuse, sexual abuse, physical neglect, and emotional neglect) and five forms of household dysfunctions (substance abuse and mental illness of a family member, intimate partner violence between parents, incarceration of a family member, and disappearance of a parent through divorce, death, or other reason) are assessed in a dichotomous manner (yes/no). A sum score of all types of experienced ACEs can be calculated (Felitti et al., 1998). No experiences of any ACE is the lowest score " 0 ," a score of " 10 " is the highest, meaning that a participant has experienced all 10 assessed forms of ACEs.

\section{Data Analyses}

Statistical analyses were performed with SPSS version 21.

Linear regression analyses were performed in order to identify factors associated to parenting and successful coping of pandemicrelated challenges. Sociodemographic variables, Covid-19 related variables (for parental satisfaction with the sharing of childcare duties: difference between parental satisfaction with the sharing of childcare duties values during and before the pandemic), and the number of experienced forms of ACEs were included into the model.

A two-way repeated measures ANOVA was used to test differences in parental satisfaction with the sharing of childcare duties before and during the pandemic (main effect time). Between groups with gender, working from home and organization of child care (main effect gender) and a differential effect of gender, working from home and organization of child care on parental satisfaction with the sharing of childcare duties over time was tested (interaction effect time $\times$ parental satisfaction with the sharing of childcare duties).

\section{RESULTS}

\section{Participants}

Primary caregivers were predominantly female ( $N=615,89.5 \%)$. The mean age of the sample was $41.4( \pm 7.4)$ years for females and $45.8( \pm 8.0)$ for males (age range f: $26-67, \mathrm{~m}: 33-71)$. The majority of the sample lived with a partner ( $\mathrm{f}$ : $N=518,84.2 \%$; $\mathrm{m}: N=65,90.3 \%)$. Academic degree of participants was generally high with the majority holding a diploma from German secondary school qualifying for university admission ("Abitur") or a university degree (f: $N=416,67.6 \%, \mathrm{~m}: N=56,77.8 \%$ ). A minority was affected financially by the pandemic, with a decreased income by more than a quarter (f: $N=69,11.2 \%$, $\mathrm{m}: N=6,8.3 \%)$.

Demographic information is displayed in Table $\mathbf{1 .}$

\section{Increase of Potential Harmful Parenting Behavior}

First, we analyzed data on increase of potential harmful parenting behavior since the beginning of the pandemic. The majority of participants stated no or moderate increase of potential harmful parenting actions. However, the question whether they had yelled more at the child was answered by $5.3 \%$ of parents with "applies very strongly." A total of $8.8 \%$ of parents reported they had been more inpatient with the child. For $2.8 \%$ of parents it applied very strongly that they had been more afraid to smack their child since the beginning of the pandemic, while for $2.2 \%$ it applied very strongly that they had been more afraid of their partner smacking their child (see Figure 1). 
TABLE 1 | Sample characteristics.

\begin{tabular}{|c|c|c|c|}
\hline & Female & Male & $p$ \\
\hline Number of participants & $615(89.5)$ & $72(10.5)$ & \\
\hline \multicolumn{4}{|l|}{ Age } \\
\hline Mean (SD) & $41.4(7.4)$ & $45.8(8.0)$ & $<0.001$ \\
\hline Age range & $26-67$ & $33-71$ & \\
\hline \multicolumn{4}{|l|}{ Highest level of education } \\
\hline University degree or diploma from secondary school & $416(67.6)$ & $56(77.8)$ & 0.079 \\
\hline Other or no school diploma & $199(32.4)$ & $16(22.2)$ & \\
\hline Decrease of income $>25 \%$ since the pandemic & $69(11.2)$ & $6(8.3)$ & 0.455 \\
\hline Working from home & $279(51.6)$ & $37(52.9)$ & 0.839 \\
\hline Living with partner & $518(84.2)$ & $65(90.3)$ & 0.175 \\
\hline \multicolumn{4}{|l|}{ Number of children in household } \\
\hline 1 & $164(30.7)$ & $22(34.4)$ & \\
\hline 2 & $263(49.3)$ & $33(51.6)$ & \\
\hline 3 & $93(17.4)$ & $7(10.9)$ & \\
\hline 4 & $11(2.1)$ & $2(3.1)$ & \\
\hline 5 & $3(0.6)$ & $0(0.0)$ & 0.663 \\
\hline \multicolumn{4}{|l|}{ Gender of the child who's birthday is next } \\
\hline Female & $274(50.6)$ & $32(49.2)$ & \\
\hline Male & $267(49.4)$ & $33(50.8)$ & 0.829 \\
\hline Mean age of the child who's birthday is next & $7.2(4.6)$ & $8.1(5.2)$ & 0.159 \\
\hline \multicolumn{4}{|l|}{ Satisfaction with sharing of childcare duties } \\
\hline Before the pandemic (M, SD) & $7.8(2.4)$ & $8.4(2.2)$ & 0.080 \\
\hline During the pandemic (M, SD) & $7.3(2.8)$ & $7.7(2.5)$ & 0.286 \\
\hline Decreased during the pandemic & $191(38.8)$ & $19(30.6)$ & 0.211 \\
\hline \multicolumn{4}{|l|}{ Childcare during the pandemic } \\
\hline Mainly by oneself & $313(59.6)$ & $6(9.4)$ & \\
\hline Mainly by partner & $28(5.3)$ & 49 (45.3) & \\
\hline Mainly equally by oneself and partner & $126(21.4)$ & $24(37.5)$ & \\
\hline Mainly by someone else (School/Kindergarden/relatives, etc.) & $58(11.0)$ & $5(7.8)$ & $<0.001$ \\
\hline Number of ACEs (M, SD) & $1.7(1.9)$ & $1.3(1.4)$ & 0.011 \\
\hline
\end{tabular}

Presented as N (\%) unless stated otherwise.

\section{Factors Associated to Parenting Behavior During the Pandemic}

The results of the regression analyses revealed that a younger age of the child $(B=-0.06, p<0.005)$, a decrease in parental satisfaction with the sharing of childcare duties compared to before the pandemic $(B=-0.84, p<0.001)$ and decreased income by more than a quarter since the beginning of the pandemic $(B=-0.51, p<0.05)$ were associated with more frequent yelling at the child.

Factors associated to higher scores for being more impatient with the child were younger age of the child $(B=-0.08$, $p<0.001)$, decreased parental satisfaction with the sharing of childcare duties compared to before the pandemic $(B=-0.09$, $p<0.001)$, and decreased income since the beginning of the pandemic $(B=-0.91, p<0.001)$.

Affirmation of the sentence "I am increasingly afraid that I will smack the child" was higher if the respective child was younger $(B=-0.04, p<0.05)$, if parental satisfaction with the sharing of childcare duties had decreased since the pandemic $(B=-0.40$, $p<0.01)$ and higher numbers of ACEs were reported $(B=0.13$, $p=0.001)$. Decreased income since the beginning of the pandemic lost significance after adding the number of ACEs into the analysis.

Concerns that the partner will smack the child were increased if participants reported a decrease of parental satisfaction with the sharing of childcare duties since the beginning of the pandemic $(B=-0.25, p<0.05)$ and if a higher number of ACEs $(B=0.15, p<0.001)$ were reported (for details see Table 2).

\section{Factors Associated to Change in Parental Satisfaction With the Sharing of Childcare Duties}

A significant decrease in parental satisfaction with the sharing of childcare duties was seen in male and female participants $(F=17.90, p<0.001)$. No significant difference regarding parental satisfaction with the sharing of childcare duties before and during the pandemic was seen for gender $(F=0.24, p=0.623)$.

Working from home during the pandemic was associated with a lower parental satisfaction with the sharing of childcare duties $(F=4.68, p<0.05)$. A stronger decrease of parental satisfaction with the sharing of childcare duties compared to before the pandemic was seen in participants who reported to have worked from home during the pandemic $(F=4.39$, $p=<0.05)$.

While parental satisfaction with the sharing of childcare duties increased in participants who reported to share caregiving equally, parental satisfaction with the sharing of childcare duties decreased if participants reported that mainly themselves or mainly their partners provided childcare $(F=20.56, p>0.001)$. Lowest grades of parental satisfaction with the sharing of childcare duties before and during the pandemic was reported by participants who reported to mainly provide care of the child by themselves $(F=13.08$, $p<0.001$; see Figure 2). 


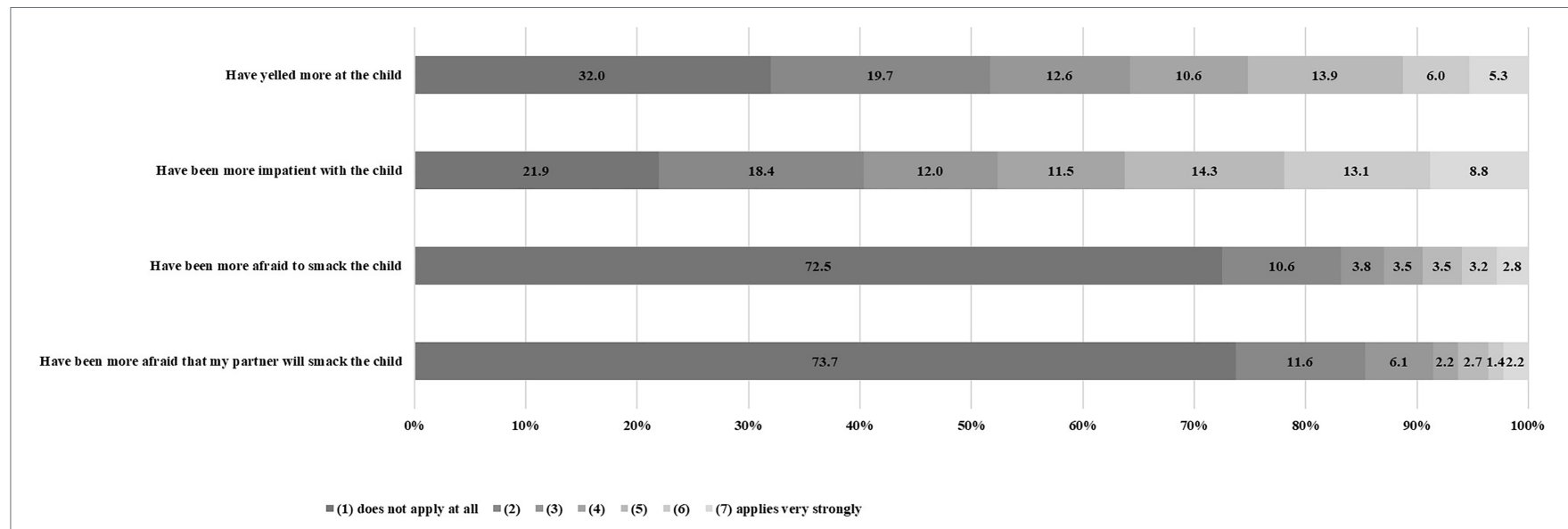

FIGURE 1 | Increase of potential harmful parenting actions since the beginning of the pandemic. Change of potential harmful parenting behavior since the beginning of the pandemic.

\section{Factors Associated to Coping With the Pandemic}

Higher scores in affirmation of the question "How well have you mastered the challenges of the Covid-19 pandemic to date?" were reported if participants did not report decrease of income since the beginning of the pandemic $(B=0.45$, $p<0.05)$ and parental satisfaction with the sharing of childcare duties had not decreased since the beginning of the pandemic $(B=1.11, p<0.001)$.

Higher scores regarding the question how well the child mastered pandemic-associated challenges were associated to a higher academic degree of participants $(B=0.34, p<0.05)$, an increase of parental satisfaction with the sharing of childcare duties since the beginning of the pandemic $(B=0.84, p<0.001)$ and a lower number of parental ACEs $(B=-0.17, p<0.001)$.

Families mastered the pandemic better if income $(B=0.57$, $p<0.05)$ and parental satisfaction with the sharing of childcare duties had not decreased since the beginning of the pandemic $(B=0.90, p<0.001$, for details see Table 3$)$.

\section{DISCUSSION}

To the best of our knowledge, this is the first study assessing the role of ACEs on paternal and maternal parenting behavior during the Covid-19 pandemic. Several factors critically predicted parenting behavior including "parental satisfaction with the sharing of childcare duties," "decrease of income since the beginning of the pandemic" and "ACEs" as the most frequent ones. Importantly, the experience of adversity during childhood or adolescence was associated with an increased concern about physical violence against the child. This is crucial, as an increase of violence within the family was hypothesized for the pandemic due to increased stress and challenges in daily life such as home schooling and working from home at the same time, reduced support, decreased leisure time activities for stress reduction, financial pressure, and reduced social control (Fegert et al., 2020b). ACEs are known to significantly increase the risk for harmful parenting behavior, including physical maltreatment, known as the "cycle of violence" (Dixon et al., 2005a,b; DuMont et al., 2007; Bailey et al., 2012; Clemens et al., 2019). Subjects who have experienced ACEs are known to have a higher stress-vulnerability (Hein and Monk, 2017; Duffy et al., 2018). The current pandemic leads to increased levels of perceived parenting stress (Brown et al., 2020; Calvano et al., 2021). The here shown data underline that parents with ACEs are at higher risk for maltreatment and suggest that targeted prevention for parents with ACEs is needed - in particular during the current pandemic.

In a German sample of more than 1,000 parents, 30\% reported an increase in children witnessing domestic violence during the pandemic, and more than $40 \%$ reported an increase in emotional abuse. Affected families were characterized by higher parental stress, job loss, and younger parent and child age (Calvano et al., 2021). In a sample of over 3,000 parents in the United States, job loss during the pandemic was associated with increased risk for child maltreatment (Lawson et al., 2020). In our sample, a decrease of household income since the beginning of the pandemic by more than a quarter was associated with increased fear of physical violence against and yelling at the child. Moreover, income decrease was associated with less well individual and familiar coping of the pandemic. Recession was proven to increase rates for all forms of child maltreatment in a wide variety of cultures (Huang et al., 2011; Schneider et al., 2017). Income loss may be associated with economic hardship and higher distress in parents - increasing pressure within families and the risk for physical and psychological violence. These results strongly underline the importance of economic support for families whose household income has fallen significantly due to the current pandemic.

Change of parental satisfaction with childcare duties was crucial for parenting behavior during the pandemic. A decrease of parental satisfaction with the sharing of childcare duties compared to before lockdown was associated with stronger concern about physical violence against the child, as withmore frequent yelling at the child, impatience and worse individual 


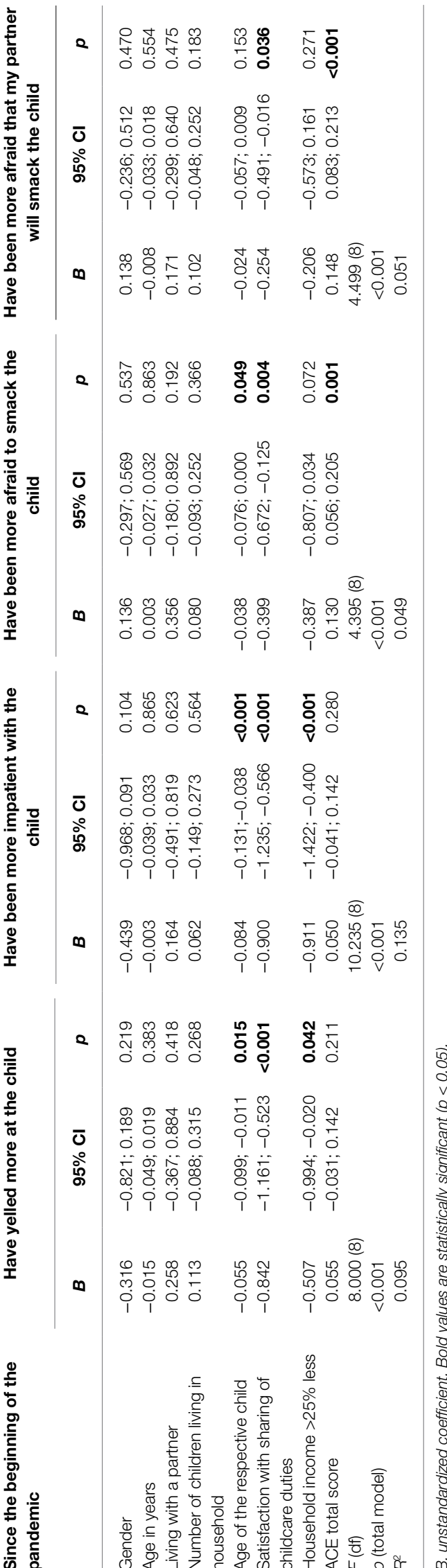

and familiar coping of the pandemic. Although for the latter ones of course a reciprocal association cannot be excluded, these results point toward the relevance of parental satisfaction with the sharing of childcare duties for parenting and mastering of the pandemic-associated challenges. Dissatisfaction with sharing of childcare duties may lead to increased parenting distress, which was shown to be associated to child abuse potential during the pandemic (Brown et al., 2020; Chung et al., 2020). In a recent study of over 800 mother-child dyads, connectedness to caregivers was an important predictor for child mental health (McArthur et al., 2021).

In our sample, parental satisfaction with the sharing of childcare duties decreased overall. In an Australian study assessing satisfaction with work-family balance and partners' share, satisfaction decreased for most parents since the beginning of the pandemic (Craig and Churchill, 2020) - being in line with our results. However, in the study by Craig and Churchill (2020), before the pandemic, women were more dissatisfied than men, while during the pandemic, this difference narrowed. In our study, no significant difference was seen in regard to gender neither before nor during the pandemic. However, as the number of male participants was very low in our sample, the validity of this result may be limited.

While nearly $60 \%$ of female participants were the main caregiver for the children during lockdown, this was only the case for $9.4 \%$ of male participant. This finding is in line with other results from German studies, showing that during lockdown, females were the main caregivers for children (Zinn et al., 2020b).

Participants who worked from home during the pandemic had a significantly higher decrease in parental satisfaction with the sharing of childcare duties compared to other participants. This is easily understandable as parents of minors working from home had to guard the children and to support them in home schooling during lockdown - likely resulting in distress and overstrain. Consequently, having the main responsibility for childcare duties was associated with lower parental satisfaction with the sharing of childcare duties. Interestingly, in participants who shared childcare equally during the pandemic, satisfaction with the sharing of childcare duties increased. This is an encouraging finding. Despite the stress of the pandemic, taking these challenges together can even improve some aspects of family life.

Several limitations of our data have to be considered. Survey participants cannot be considered as representative for the general public, as data are based on a non-probability sample. Compared to data of a sample of parents derived from the Socio Economic Panel, a probability sample in Germany, assessed in a similar time frame, in our sample parents had a higher education, more children in the respective household were reported and rate of participants having a partner was higher (Zinn et al., 2020a). Therefore, the findings cannot be generalized for all families. As lower education correlates with higher rates of child maltreatment (Kotch et al., 1995; Berthold et al., 2019), the results of this study may tend to underestimate the negative impact of the pandemic on families. Accordingly, the results shown should be interpreted as an indication of possibly even 


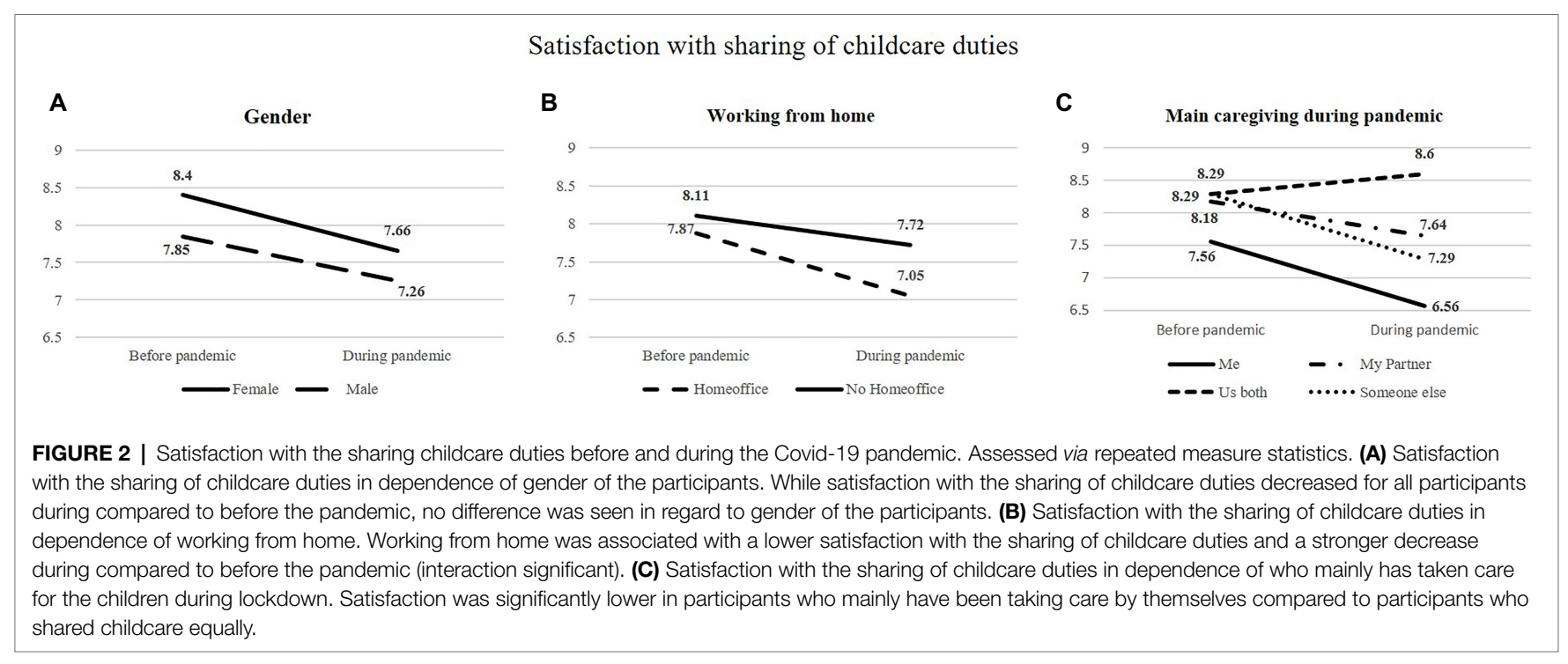

TABLE 3 | Factors associated to coping of the pandemic.

\begin{tabular}{|c|c|c|c|c|c|c|c|c|c|}
\hline & \multicolumn{3}{|c|}{$\begin{array}{l}\text { How well oneself has mastered the } \\
\text { challenges of the pandemic }\end{array}$} & \multicolumn{3}{|c|}{$\begin{array}{l}\text { How well the child has mastered the } \\
\text { challenges of the pandemic }\end{array}$} & \multicolumn{3}{|c|}{$\begin{array}{l}\text { How well the family has mastered the } \\
\text { challenges of the pandemic }\end{array}$} \\
\hline & $B$ & $95 \% \mathrm{Cl}$ & $p$ & $B$ & $95 \% \mathrm{Cl}$ & $p$ & B & $95 \% \mathrm{Cl}$ & $p$ \\
\hline $\begin{array}{l}\text { Gender } \\
\text { Age in years } \\
\text { Living with a partner } \\
\text { Number of children living in } \\
\text { household }\end{array}$ & $\begin{array}{l}-0.090 \\
-0.012 \\
-0.339 \\
-0.049\end{array}$ & $\begin{array}{l}-0.524 ; 0.344 \\
-0.044 ; 0.019 \\
-0.888 ; 0.210 \\
-0.233 ; 0.135\end{array}$ & $\begin{array}{l}0.685 \\
0.447 \\
0.226 \\
0.603\end{array}$ & $\begin{array}{c}-0.224 \\
-0.011 \\
0.157 \\
0.033\end{array}$ & $\begin{array}{l}-0.689 ; 0.242 \\
-0.045 ; 0.022 \\
-0.433 ; 0.746 \\
-0.168 ; 0.234\end{array}$ & $\begin{array}{l}0.345 \\
0.506 \\
0.601 \\
0.749\end{array}$ & $\begin{array}{l}0.094 \\
-0.029 \\
-0.024 \\
-0.016\end{array}$ & $\begin{array}{l}-0.341 ; 0.530 \\
-0.060 ; 0.003 \\
-0.576 ; 0.527 \\
-0.200 ; 0.169\end{array}$ & $\begin{array}{l}0.671 \\
0.075 \\
0.931 \\
0.868\end{array}$ \\
\hline $\begin{array}{l}\text { Age of the respective child } \\
\text { Education } \\
\text { Household income }>25 \% \text { less } \\
\text { Satisfaction with sharing of } \\
\text { childcare duties }\end{array}$ & $\begin{array}{l}0.027 \\
0.039 \\
0.449 \\
1.108\end{array}$ & $\begin{array}{c}-0.014 ; 0.068 \\
-0.267 ; 0.345 \\
0.003 ; 0.895 \\
0.818 ; 1.398\end{array}$ & $\begin{array}{c}0.200 \\
0.802 \\
\mathbf{0 . 0 4 8} \\
<0.001\end{array}$ & $\begin{array}{c}-0.041 \\
0.340 \\
0.235 \\
0.844\end{array}$ & $\begin{array}{c}-0.085 ; 0.004 \\
0.012 ; 0.668 \\
-0.243 ; 0.714 \\
0.534 ; 1.155\end{array}$ & $\begin{array}{c}0.071 \\
\mathbf{0 . 0 4 3} \\
0.334 \\
<0.001\end{array}$ & $\begin{array}{c}-0.001 \\
0.091 \\
0.566 \\
0.901\end{array}$ & $\begin{array}{c}-0.042 ; 0.040 \\
-0.216 ; 0.398 \\
0.118 ; 1.014 \\
0.610 ; 1.191\end{array}$ & $\begin{array}{c}0.960 \\
0.559 \\
\mathbf{0 . 0 1 3} \\
<\mathbf{0 . 0 0 1}\end{array}$ \\
\hline $\begin{array}{l}\text { Working from home } \\
\text { ACE total score } \\
F(\text { df) }\end{array}$ & $\begin{array}{c}0.151 \\
-0.051 \\
7.221(10)\end{array}$ & $\begin{array}{l}-0.136 ; 0.437 \\
-0.129 ; 0.437\end{array}$ & $\begin{array}{l}0.302 \\
0.191\end{array}$ & $\begin{array}{c}0.069 \\
-0.172 \\
6.863(10)\end{array}$ & $\begin{array}{c}-0.238 ; 0.376 \\
-0.255 ;-0.088\end{array}$ & $\begin{array}{l}0.660 \\
<0.001\end{array}$ & $\begin{array}{c}0.131 \\
-0.058 \\
5.461(10)\end{array}$ & $\begin{array}{l}-0.157 ; 0.418 \\
-0.135 ; 0.020\end{array}$ & $\begin{array}{l}0.371 \\
0.144\end{array}$ \\
\hline
\end{tabular}

$B$, unstandardized coefficient. Bold values are statistically significant $(p<0.05)$.

greater stress in affected families. Questions on parenting before the pandemic are based on retrospective self-report, just as questions regarding ACEs, which may impair validity due to recall bias. There has been a critical debate on the validity of retrospectively assessed ACEs (Baldwin et al., 2019), but subjective reports of childhood maltreatment were shown to be highly relevant for adulthood (Danese and Widom, 2020). As to the best of our knowledge, no data on parenting during the Covid-19 pandemic are known yet from cohorts assessing ACEs and parenting prospectively, our findings are of high relevance.

In our cross-sectional study, causality cannot be deduced. Reciprocal associations - such as between parental satisfaction with the sharing of childcare duties and parenting behavior are likely. However, the presented results give an important insight into the relevance of factors such as economic pressure, parental satisfaction with the sharing of childcare duties, and ACEs on parenting during and coping with the pandemic. As the impact of economic pressure was already significant in our highly educated sample, it can be assumed that the impact of economic hardship may be even more relevant in a sample with a lower socioeconomic status, and consequently in a more representative sample.

Taken together, younger age of the child, economic pressure, dissatisfaction with the sharing of childcare duties, and ACEs are significantly associated with potential harmful parenting behavior during the Covid-19 pandemic. There is a need for targeted support for parents with ACEs and dissatisfaction with their family model regarding caregiving. Models where both parents share childcare duties shall equally be encouraged. Economic support is needed for families who have lost a significant part of their income due to the pandemic. 


\section{DATA AVAILABILITY STATEMENT}

The raw data supporting the conclusions of this article was made available by the authors on reasonable request.

\section{ETHICS STATEMENT}

Ethical review and approval was not required for the study on human participants in accordance with the local legislation and institutional requirements. The patients/participants provided their written informed consent to participate in this study.

\section{REFERENCES}

Bailey, H. N., DeOliveira, C. A., Wolfe, V. V., Evans, E. M., and Hartwick, C. (2012). The impact of childhood maltreatment history on parenting: a comparison of maltreatment types and assessment methods. Child Abuse Negl. 36, 236-246. doi: 10.1016/j.chiabu.2011.11.005

Baldwin, J. R., Reuben, A., Newbury, J. B., and Danese, A. (2019). Agreement between prospective and retrospective measures of childhood maltreatment: a systematic review and meta-analysis. JAMA Psychiatry 76, 584-593. doi: 10.1001/jamapsychiatry.2019.0097

Berthold, O., Clemens, V., Witt, A., Brahler, E., Plener, P. L., and Fegert, J. M. (2019). Awareness of abusive head trauma in a German population-based sample: implications for prevention. Pediatr. Res. 86, 537-541. doi: 10.1038/ s41390-019-0467-8

Brown, S. M., Doom, J. R., Lechuga-Peña, S., Watamura, S. E., and Koppels, T. (2020). Stress and parenting during the global COVID-19 pandemic. Child Abuse Negl. 110:104699. doi: 10.1016/j.chiabu.2020.104699

Bunea, I. M., Szentágotai-Tătar, A., and Miu, A. C. (2017). Early-life adversity and cortisol response to social stress: a meta-analysis. Transl. Psychiatry 7:1274. doi: 10.1038/s41398-017-0032-3

Calvano, C., Engelke, L., Di Bella, J., Kindermann, J., Renneberg, B., and Winter, S. M. (2021). Families in the COVID-19 pandemic: parental stress, parent mental health and the occurrence of adverse childhood experiencesresults of a representative survey in Germany. Eur. Child Adolesc. Psychiatry 1-13. doi: 10.1007/s00787-021-01739-0 [Epub ahead of print].

Chung, G., Lanier, P., and Wong, P. Y. J. (2020). Mediating effects of parental stress on harsh parenting and parent-child relationship during coronavirus (COVID-19) pandemic in Singapore. J. Fam. Violence 1-12. doi: 10.1007/ s10896-020-00200-1 [Epub ahead of print]

Clemens, V., Berthold, O., Witt, A., Sachser, C., Brähler, E., Plener, P. L., et al. (2019). Child maltreatment is mediating long-term consequences of household dysfunction in a population representative sample. Eur. Psychiatry 58, 10-18. doi: 10.1016/j.eurpsy.2019.01.018

Clemens, V., Huber-Lang, M., Plener, P. L., Brahler, E., Brown, R. C., and Fegert, J. M. (2018). Association of child maltreatment subtypes and longterm physical health in a German representative sample. Eur. J. Psychotraumatol. 9:1510278. doi: 10.1080/20008198.2018.1510278

Compas, B. E., Jaser, S. S., Bettis, A. H., Watson, K. H., Gruhn, M. A., Dunbar, J. P., et al. (2017). Coping, emotion regulation, and psychopathology in childhood and adolescence: a meta-analysis and narrative review. Psychol. Bull. 143, 939-991. doi: 10.1037/bul0000110

Craig, L., and Churchill, B. (2020). Dual-earner parent couples' work and care during COVID-19. Gend. Work. Organ. 28, 66-79. doi: 10.1111/gwao.12497

Danese, A., and Widom, C. S. (2020). Objective and subjective experiences of child maltreatment and their relationships with psychopathology. Nat. Hum. Behav. 4, 811-818. doi: 10.1038/s41562-020-0880-3

Dixon, L., Browne, K., and Hamilton-Giachritsis, C. (2005a). Risk factors of parents abused as children: a mediational analysis of the intergenerational continuity of child maltreatment (part I). J. Child Psychol. Psychiatry 46, 47-57. doi: 10.1111/j.1469-7610.2004.00339.x

Dixon, L., Hamilton-Giachritsis, C., and Browne, K. (2005b). Attributions and behaviours of parents abused as children: a mediational analysis of the

\section{AUTHOR CONTRIBUTIONS}

VC interpreted the data and wrote the manuscript. FK-D and UZ supported recruitment of the sample. JF conceptualized the survey and supervised data analyses. All authors contributed to the article and approved the submitted version.

\section{ACKNOWLEDGMENTS}

We thank all participants of our study.

intergenerational continuity of child maltreatment (part II). J. Child Psychol. Psychiatry 46, 58-68. doi: 10.1111/j.1469-7610.2004.00340.x

Duffy, K. A., McLaughlin, K. A., and Green, P. A. (2018). Early life adversity and health-risk behaviors: proposed psychological and neural mechanisms. Ann. N. Y. Acad. Sci. 1428, 151-169. doi: 10.1111/nyas.13928

DuMont, K. A., Widom, C. S., and Czaja, S. J. (2007). Predictors of resilience in abused and neglected children grown-up: the role of individual and neighborhood characteristics. Child Abuse Negl. 31, 255-274. doi: 10.1016/j. chiabu.2005.11.015

Elder, G. H. J. (1974). Children of the Great Depression: Social Changes in Life Experience. Boulder, CO, USA: University of Chicago Press.

Elder, G. H. J., and Conger, R. D. (2000). Children of the Land: Adversity and Success in Rural America. Chicago, IL, USA: University of Chicago Press.

Fegert, J. M., Berthold, O., Clemens, V., and Kölch, M. (2020a). COVID-19Pandemie: Kinderschutz ist systemrelevant. Dtsch. Arztebl. Int. 117:A-703.

Fegert, J. M., Vitiello, B., Plener, P. L., and Clemens, V. (2020b). Challenges and burden of the coronavirus 2019 (COVID-19) pandemic for child and adolescent mental health: a narrative review to highlight clinical and research needs in the acute phase and the long return to normality. Child Adolesc. Psychiatry Ment. Health 14:20. doi: 10.1186/s13034-020-00329-3

Felitti, V. J., Anda, R. F., Nordenberg, D., Williamson, D. F., Spitz, A. M., Edwards, V., et al. (1998). Relationship of childhood abuse and household dysfunction to many of the leading causes of death in adults: the adverse childhood experiences (ACE) study. Am. J. Prev. Med. 14, 245-258. doi: 10.1016/S0749-3797(98)00017-8

Fong, C. V., and Iarocci, G. (2020). Child and family outcomes following pandemics: a systematic review and recommendations on COVID-19 policies. J. Pediatr. Psychol. 45, 1124-1143. doi: 10.1093/jpepsy/jsaa092

Hein, T. C., and Monk, C. S. (2017). Research review: neural response to threat in children, adolescents, and adults after child maltreatment - a quantitative meta-analysis. J. Child Psychol. Psychiatry 58, 222-230. doi: 10.1111/jcpp.12651

Huang, M. I., O'Riordan, M. A., Fitzenrider, E., McDavid, L., Cohen, A. R., and Robinson, S. (2011). Increased incidence of nonaccidental head trauma in infants associated with the economic recession. J. Neurosurg. Pediatr. 8:171. doi: $10.3171 / 2011.5$.PEDS1139

Hughes, K., Bellis, M. A., Hardcastle, K. A., Sethi, D., Butchart, A., Mikton, C., et al. (2017). The effect of multiple adverse childhood experiences on health: a systematic review and meta-analysis. Lancet Public Health 2, e356-e366. doi: 10.1016/S2468-2667(17)30118-4

Hunter, R. S., and Kilstrom, N. (1979). Breaking the cycle in abusive families. Am. J. Psychiatry 136, 1320-1322. doi: 10.1176/ajp.136.10.1320

Imperial College COVID-19 Response Team (2020). Estimating the number of infections and the impact of non-pharmaceutical interventions on COVID-19 in 11 European countries. Available at: https://www.imperial. ac.uk/media/imperial-college/medicine/sph/ide/gida-fellowships/ImperialCollege-COVID19-Europe-estimates-and-NPI-impact-30-03-2020.pdf (Accessed March 21, 2021)

Köhler-Dauner, F., Clemens, V., Hildebrand, K., Ziegenhain, U., and Fegert, J. M. (2021). The interplay between maternal childhood maltreatment, parental coping strategies as well as endangered parenting behavior during the current SARS-CoV-2 pandemic. Dev. Child Welfare 3, 71-84. doi: 10.1177/ 25161032211014899 
Kotch, J. B., Browne, D. C., Ringwalt, C. L., Stewart, P. W., Ruina, E., Holt, K., et al. (1995). Risk of child abuse or neglect in a cohort of low-income children. Child Abuse Negl. 19, 1115-1130. doi: 10.1016/0145-2134(95)00072G

Lawson, M., Piel, M. H., and Simon, M. (2020). Child maltreatment during the COVID-19 pandemic: consequences of parental job loss on psychological and physical abuse towards children. Child Abuse Negl. 110:104709. doi: 10.1016/j.chiabu.2020.104709

Leitenberg, H., Gibson, L. E., and Novy, P. L. (2004). Individual differences among undergraduate women in methods of coping with stressful events: the impact of cumulative childhood stressors and abuse. Child Abuse Negl. 28, 181-192. doi: 10.1016/j.chiabu.2003.08.005

Marchetti, D., Fontanesi, L., Mazza, C., Di Giandomenico, S., Roma, P., and Verrocchio, M. C. (2020). Parenting-related exhaustion during the Italian COVID-19 lockdown. J. Pediatr. Psychol. 45, 1114-1123. doi: 10.1093/jpepsy/ jsaa093

McArthur, B. A., Racine, N., McDonald, S., Tough, S., and Madigan, S. (2021). Child and family factors associated with child mental health and well-being during COVID-19. Eur. Child Adolesc. Psychiatry doi: 10.1007/ s00787-021-01849-9 [Epub ahead of print].

Nguyen, L. H. (2021). Calculating the impact of COVID-19 pandemic on child abuse and neglect in the U.S. Child Abuse Negl. 118:105136. doi: 10.1016/j. chiabu.2021.105136

Norman, R. E., Byambaa, M., De, R., Butchart, A., Scott, J., and Vos, T. (2012). The long-term health consequences of child physical abuse, emotional abuse, and neglect: a systematic review and meta-analysis. PLoS Med. 9:e1001349. doi: 10.1371/journal.pmed.1001349

Rehkopf, D. H., Headen, I., Hubbard, A., Deardorff, J., Kesavan, Y., Cohen, A. K., et al. (2016). Adverse childhood experiences and later life adult obesity and smoking in the United States. Ann. Epidemiol. 26, 488.e485-492.e485. doi: 10.1016/j.annepidem.2016.06.003

Romero, E., López-Romero, L., Domínguez-Álvarez, B., Villar, P., and Gómez-Fraguela, J. A. (2020). Testing the effects of COVID-19 confinement in Spanish children: the role of parents' distress, emotional problems and specific parenting. Int. J. Environ. Res. Public Health 17:6975. doi: 10.3390/ ijerph17196975

Salt, E., Wiggins, A. T., Cooper, G. L., Benner, K., Adkins, B. W., Hazelbaker, K., et al. (2021). A comparison of child abuse and neglect encounters before and after school closings due to SARS-Cov-2. Child Abuse Negl. 118:105132. doi: 10.1016/j.chiabu.2021.105132

Schneider, W., Waldfogel, J., and Brooks-Gunn, J. (2017). The great recession and risk for child abuse and neglect. Child Youth Serv. Rev. 72, 71-81. doi: 10.1016/j.childyouth.2016.10.016

Sheffler, J. L., Piazza, J. R., Quinn, J. M., Sachs-Ericsson, N. J., and Stanley, I. H. (2019). Adverse childhood experiences and coping strategies: identifying pathways to resiliency in adulthood. Anxiety Stress Coping 32, 594-609. doi: 10.1080/10615806.2019.1638699

Thomson, P., and Jaque, S. V. (2017). Adverse childhood experiences (ACE) and adult attachment interview (AAI) in a non-clinical population. Child Abuse Negl. 70, 255-263. doi: 10.1016/j.chiabu.2017.06.001

UNESCO (2020). COVID-19 educational disruption and response. Available at: https://en.unesco.org/covid19/educationresponse (Accessed February 24, 2021).

van Tilburg, M. A. L., Edlynn, E., Maddaloni, M., van Kempen, K., DíazGonzález de Ferris, M., and Thomas, J. (2020). High levels of stress due to the SARS-CoV-2 pandemic among parents of children with and without chronic conditions across the USA. Children 7:193. doi: 10.3390/ children7100193

Wingenfeld, K., Schäfer, I., Terfehr, K., Grabski, H., Driessen, M., Grabe, H., et al. (2011). Reliable, valide und ökonomische Erfassung früher Traumatisierung: Erste psychometrische Charakterisierung der deutschen Version des Adverse Childhood Experiences Questionnaire (ACE). Psychother. Psychosom. Med. Psychol. 61, e10-e14. doi: 10.1055/s-0030-1263161

Witt, A., Fegert, J. M., Rodens, K. P., Brähler, E., Luhrs Da Silva, C., and Plener, P. L. (2017). The cycle of violence: examining attitudes toward and experiences of corporal punishment in a representative German sample. J. Interpers. Violence 36, NP263-NP286. doi: 10.1177/0886260517731784

Witt, A., Sachser, C., Plener, P. L., Brähler, E., and Fegert, J. M. (2019). The prevalence and consequences of adverse childhood experiences in the German population. Dtsch. Arztebl. Int. 116, 635-642. doi: 10.3238/arztebl.2019.0635

Wright, K. A., Turanovic, J. J., O’Neal, E. N., Morse, S. J., and Booth, E. T. (2019). The cycle of violence revisited: childhood victimization, resilience, and future violence. J. Interpers. Violence 34, 1261-1286. doi: $10.1177 / 0886260516651090$

Zinn, S., Bayer, M., Entringer, T., Goebel, J., Grabka, M. M., Graeber, D., et al. (2020a). Subjektive Belastung der Eltern durch Schulschließungen zu Zeiten des Corona-bedingten Lockdowns. Available at: https://www.diw.de/documents/ publikationen/73/diw_01.c.794185.de/diw_sp1097.pdf (Accessed March 21, 2021).

Zinn, S., Kreyenfeld, M., and Bayer, M. (2020b). Kinderbetreuung in CoronaZeiten: Mütter tragen die Hauptlast, aber Väter holen auf. Available at: https://www.diw.de/documents/publikationen/73/diw_01.c.794303.de/diw_ aktuell_51.pdf (Accessed March 21, 2021).

Conflict of Interest: JF has received research funding from the EU, DFG (German Research Foundation), BMG (Federal Ministry of Health), BMBF (Federal Ministry of Education and Research), BMFSFJ (Federal Ministry of Family, Senior Citizens, Women and Youth), G-BA Innovationsfonds, several state ministries, State Foundation Baden-Württemberg, Volkswagen Foundation, Porticus Foundation, and Diocese of Rottenburg-Stuttgart. Moreover, JF received travel grants, honoraria, and sponsoring for conferences and medical educational purposes from APK, Deutschlandfunk, DFG, DJI, DKSB, Infectopharm, med update, UNICEF, several universities, professional associations, political foundations, and German federal and state ministries during the last 5 years. JF holds no stocks of pharmaceutical companies.

The remaining authors declare that the research was conducted in the absence of any commercial or financial relationships that could be construed as a potential conflict of interest.

Publisher's Note: All claims expressed in this article are solely those of the authors and do not necessarily represent those of their affiliated organizations, or those of the publisher, the editors and the reviewers. Any product that may be evaluated in this article, or claim that may be made by its manufacturer, is not guaranteed or endorsed by the publisher.

Copyright (c) 2021 Clemens, Köhler-Dauner, Ziegenhain and Fegert. This is an openaccess article distributed under the terms of the Creative Commons Attribution License (CC BY). The use, distribution or reproduction in other forums is permitted, provided the original author(s) and the copyright owner(s) are credited and that the original publication in this journal is cited, in accordance with accepted academic practice. No use, distribution or reproduction is permitted which does not comply with these terms. 